\title{
Secondary Hypertrophic Osteoarthropathy or Pierre-Marie Syndrome Bamberger: Clinical Case and Literature Review
}

\author{
Kaba Condé1,2, Carlos Othon Guelngar², Awada Mohamed1, Igué Kadidjatou2, \\ Douna Granga Daouya3 ${ }^{3}$, Mamadou Ciré Barry4, Mamadou Hady Diallo², Karinka Diawara², \\ Konaté Mamady², Touré Moriba1, Fodé Abass Cissé2
}

${ }^{1}$ Department of Rheumatology, Academic Hospital, University of Conakry, Conakry, Guinea

${ }^{2}$ Department of Neurology, Academic Hospital, University of Conakry, Conakry, Guinea

${ }^{3}$ Department of Pediatric, Mother and child Hospital, Ndjamena, Chad

${ }^{4}$ Department of Pediatric, Academic Hospital, University of Conakry, Conakry, Guinea

Email: Condekba95@yahoo.fr, car1325@yahoo.fr, awadamohamed2@gmail.com, kadigue95@gmail.com, drbarrymckadi08@yahoo.fr, hadyd08@gmail.com, diawarakarinka@yahoo.fr, medkonate90@gmail.com, touremoriba@yahoo.fr,dounag@yahoo.fr, abass3002yahoo.fr

How to cite this paper: Condé, K., Guelngar, C.O., Mohamed, A., Kadidjatou, I., Daouya, D.G., Barry, M.C., Diallo, M.H., Diawara, K., Mamady, K., Moriba, T. and Cissé, F.A. (2021) Secondary Hypertrophic Osteoarthropathy or Pierre-Marie Syndrome Bamberger: Clinical Case and Literature Review. Open Journal of Rheumatology and Autoimmune Diseases, 11, 73-78. https://doi.org/10.4236/ojra.2021.112009

Received: December 8, 2020

Accepted: May 17, 2021

Published: May 20, 2021

Copyright $\odot 2021$ by author(s) and Scientific Research Publishing Inc. This work is licensed under the Creative Commons Attribution International License (CC BY 4.0).

http://creativecommons.org/licenses/by/4.0/

\begin{abstract}
Secondary hypertrophic osteoarthropathy, or Pierre-Marie Bamberger syndrome, is characterized by the association of digital clubbing, polyarthritis and periostitis affecting the long bones. Most commonly it is a paraneoplastic syndrome associated with lung cancer in $80 \%$ of cases. We report the case of a 49-year-old female patient who is actively smoking, one pack per day for 20 years. Seen in consultation for pain and swelling of the hands, elbows, knees, ankles, and feet evolving for about 5 months, associated with a poorly differentiated pulmonary adenocarcinoma. On history, she told us about a weight loss of about $8 \mathrm{~kg}$, no fever, no cough, no family history of inflammatory rheumatism or cancer. Bilateral digital clubbing was noted. The diagnosis was based on imaging and histology. Treatment with nonsteroidal anti-inflammatory drugs (NSAIDs) and chemo-radiotherapy was started.
\end{abstract}

\section{Keywords}

Hypertrophic Osteoarthropathy, Pulmonary Adenocarcinoma, Guinea

\section{Introduction}

Hypertrophic osteoarthropathy (HOA), also called Pierre Marie Bamberger syndrome, was described at the end of the 19th century [1]. It is characterized by 
a combination of clinical findings of severe disabling arthralgia and arthritis, digital clubbing, and periostosis of tubular bones, with or without synovial effusion [2] [3]. HOA can occur as a primary familial autosomal dominant condition called pachydermoperiostosis or secondary to other diseases in (95\% to $97 \%$ of cases) [1] [4]. The secondary forms are due to a wide range of diseases, most frequently by paraneoplastic syndromes which are associated with lung cancer in $80 \%$ of cases [5]. The pathophysiology of these two syndromes seems poorly understood, but there is vasodilation in the phalanges with transudate to the interstitium. Palmar angiograms confirm the increase in size and number of digital capillaries. The responsible for this vasodilation would be a humoral substance normally inhibited by the pulmonary capillaries, and therefore, present in the right-left shunts [6]. A hormonal trail is also retained in HAE. A Growth Hormone-like secreted by bronchial and gastric carcinomas is thought to be responsible for the proliferation of the periosteum [7]. Finally, it should be noted the probable role of the parasympathetic system in these vasodilations with regard to the improvement of symptoms after selective vagotomy [8].

We report the case of a 49 -year-old female patient with secondary hypertrophic osteoarthropathy.

\section{Observation}

\section{Patient informed consent was obtained for publication of the case and asso- ciated images}

A 49-year-old woman with a history of asthma and depression, active smoking, one pack a day for 20 years, seen in consultation for pain and swelling of the hands, elbows, knees, ankles, and feet evolving for about 5 months. On history, she reported a weight loss of about $8 \mathrm{~kg}$, no fever, no cough, no family history of inflammatory rheumatism or cancer. She is not taking any medication except Pulmicort and Ventolin. The clinical examination noted swelling in the hands, ankles and feet and synovitis of the elbow and left knee. Bilateral digital clubbing was noted. On the respiratory system, the vesicular murmur was perfectly perceived in the two fields, without additional sound. The lymph node areas remained free.

The biological workup showed a biological inflammatory syndrome with an erythrocyte sedimentation rate (ESR) accelerated to $58 \mathrm{~mm}$ (normal value: 20 $\mathrm{mm} / \mathrm{h}$ ) at the $1^{\text {st }}$ hour and a positive C reactive protein (CRP) at $102 \mathrm{mg} / \mathrm{l}$ (normal value: $<6 \mathrm{mg} / \mathrm{l})$. The immunological and infectious results were negative.

The $\mathrm{x}$-ray of the hands, feet, forearms and legs showed periosteal apposition at the shaft of the long bones (Figure 1) and the bone scan also showed hyper fixation at the long bone level. The chest $\mathrm{x}$-ray noted a triangular opacity in the upper right lobe (Figure 2(a)).

Additional investigations, in particular the chest CT scan, showed a right supra-hilar tumour mass invading the right upper mediastinum associated with multiple supracimimetric lymphadenopathies especially in the right upper mediastinum (Figure 2(b)). The PET scan showed a large heterogeneous and 


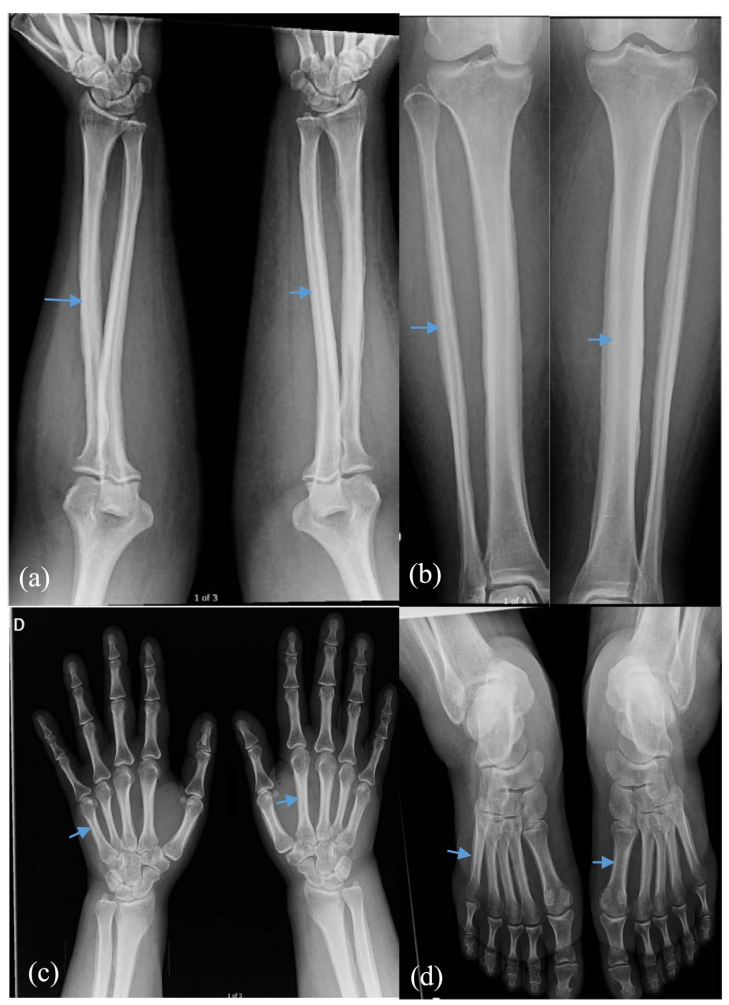

Figure 1. X-ray of forearms (a), legs (b), hands (c) and feet (d) showed a periosteal apposition at the level of the long bones.

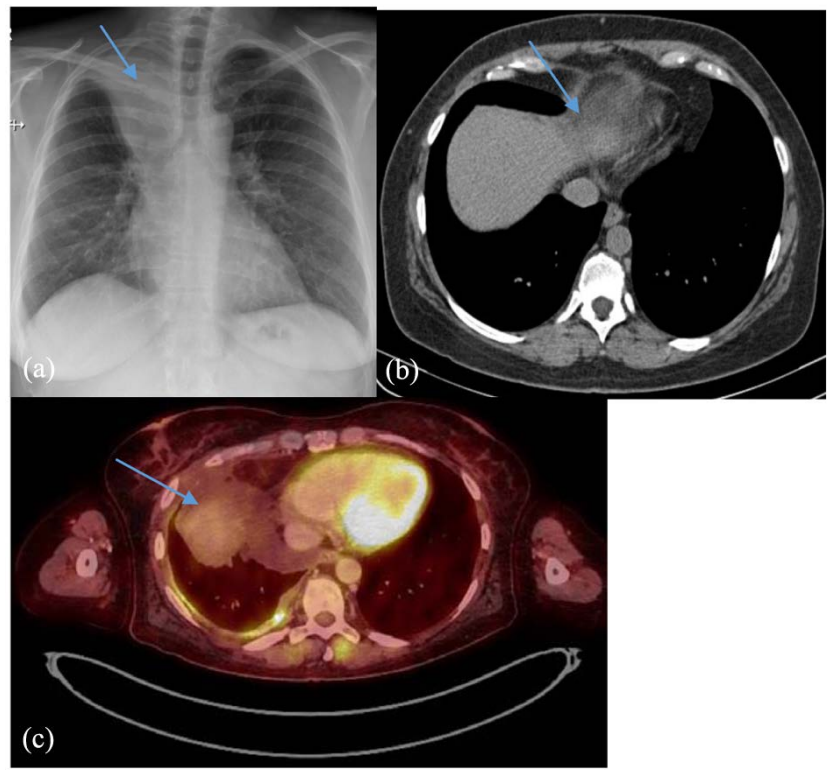

Figure 2. (a) Chest x-ray showed triangular opacity in the right upper lobe; (b) Chest CT scan showed a right suprahilar tumour mass invading the superior mediastinum. PET-scan; (c) showed a large heterogeneous and intensely hyper-metabolic right suprahilar mass.

intensely hyper-metabolic right supra-hilar mass (Figure 2(c)). The bronchial biopsy showed a poorly differentiated lung carcinoma. Treatment with nonste- 
roidal anti-inflammatory drugs (NSAIDs) and chemotherapy couple with radiotherapy was started.

After a 3-month follow-up, the joint damage disappeared as long as there was a worsening of the respiratory symptoms and the patient was hospitalized in intensive care or she died three weeks after admission.

\section{Discussion}

$\mathrm{HAO}$ is a syndrome characterized by the association of digital clubbing, polyarthritis and periostitis affecting the long bones [2] [3].

The precise incidence and prevalence of HAO is unknown [9]. The age of onset has a bimodal distribution, with the initial peak occurring in the first year of life and the other during puberty.

Most affected are males; research has described both autosomal dominant and recessive inheritance.

HAO can be of primary genetic origin (autosomal dominant) called pachydermoperiostosis [10]. Much more often, it is a secondary manifestation due to a wide range of disease, most commonly paraneoplastic syndromes which are associated with lung cancer [11]. However, other non-neoplastic lung diseases have been mentioned, such as infections, inflammatory diseases (sarcoidosis), arteriovenous malformations, and extra-pulmonary diseases, such as cardiovascular disease, cirrhosis, and chronic inflammatory bowel disease [12]. Malignant lung tumours, whether primary or metastatic, are responsible for approximately $80 \%$ of secondary HAO cases, and most patients are diagnosed with adenocarcinoma as reported in our case [4] [7] [12]. There is no gender predominance, and the average age is 55 to 75 years [13]. However, in our case, the patient was 49-year-old.

The etiopathogenesis of secondary hypertrophic osteoarthropathy has been largely attributed to a neurogenic or vascular pathway triggered by circulating growth factors. The vascular pathway can be classified into two subtypes: 1) hypersecretion of vasoactive agents by the tumour itself or hypoxemia and 2) mechanical release of vasoactive agents into the systemic circulation due to 'an arteriovenous shunt in the pulmonary circulation [13] [14]. There is also evidence that circulating growth factors, such as platelet-derived growth factor (PDGF), vascular endothelial growth factor (VEGF) or prostaglandin E2 (PGE2), cause the triad (digital clubbing, polyarthritis and periostitis) [14], promoting angiogenesis, vasodilation, hyperplasia, interstitial oedema and collagen deposition in tissues [14] [15] [16].

The prognosis and treatment of secondary $\mathrm{HAO}$ are naturally linked to the primary aetiology [17]. Definitive treatment aims to remedy the underlying cause, including surgical resection, definitive chemotherapy or radiofrequency ablation for a primary malignancy of the lung [17] [18]. Symptomatic treatment (NSAIDs, octreotide, bisphosphonates, and specific growth factor inhibitors) is used in patients in whom the primary aetiology cannot be treated [19]. 


\section{Conclusion}

The diagnosis of hypertrophic osteoarthropathy is based on clinical and radiographic evidence. It is considered that a paraneoplastic syndrome associated with lung cancer in $80 \%$ of cases. The prognosis and treatment of secondary hypertrophic osteoarthropathy are naturally linked to the primary aetiology.

\section{Conflicts of Interest}

The authors declare that they have no conflicts of interest.

\section{References}

[1] Yap, F.Y., Skalski, M.R., Patel, D.B., et al. (2017) Hypertrophic Osteoarthropathy: Clinical and Imaging Features. RadioGraphics, 37, 157-195.

https://doi.org/10.1148/rg.2017160052

[2] Mauricio, O., Francis, L., Athar, U., et al. (2009) Hypertrophic Osteoarthropathy Masquerading as Lower Extremity Cellulitis and Response to Bisphosphonates. Journal of Thoracic Oncology, 4, 260-262. https://doi.org/10.1097/JTO.0b013e3181952915

[3] Ribigan, A.C., Bajenaru, O.L., Antochi, F.A. and Bajenaru, O.A. (2019) Nociceptive Pain Unmasking a Serious Pathology-Paraneoplastic Hypertrophic Osteoarthropathy: A Case Report. Medicine (Baltimore), 98, e15900. https://doi.org/10.1097/MD.0000000000015900

[4] Yao, Q., Altman, R.D. and Brahn, E. (2009) Periostitis and Hypertrophic Pulmonary Osteoarthropathy: Report of 2 Cases and Review of the Literature. Seminars in Arthritis and Rheumatism, 38, 458-466. https://doi.org/10.1016/j.semarthrit.2008.07.001

[5] Nobuhiro, K., Naoki, W., Nobuyuki, K., et al. (2014) Paraneoplastic Syndromes Associated with Lung Cancer. World Journal of Clinical Oncology, 5, 197-223. https://doi.org/10.5306/wjco.v5.i3.197

[6] Rouers, A., Radermecker, M.A., Duysinx, B., Kaschten, B. and Limet, R. (2006) LE CAS CLINIQUE DU MOIS Le syndrome de Pierre-Marie Bamberger. Revue Médicale de Liège, 61, 142-144.

[7] Nakonechnaya, A.O. and Shewchuk, B.M. (2015) Growth Hormone Enhances LNCaP Prostate Cancer Cell Motility. Endocrine Research, 40, 97-105. https://doi.org/10.3109/07435800.2014.966383

[8] Goldstein, D.S. (2013) Differential Responses of Components of the Autonomic Nervous System. In: Buijs, R.M. and Swaab, D.F., Eds., Handbook of Clinical Neurology, Volume 117, Elsevier, 13-22.

http://www.sciencedirect.com/science/article/pii/B978044453491000002X https://doi.org/10.1016/B978-0-444-53491-0.00002-X

[9] Zhang, Z., Zhang, C. and Zhang, Z. (2013) Primary Hypertrophic Osteoarthropathy: An Update. Frontiers of Medicine, 7, 60-64.

https://doi.org/10.1007/s11684-013-0246-6

[10] Tan, I., Lomasney, L., Stacy, G.S., Lazarus, M. and Mar, W.A. (2019) Spectrum of Voriconazole-Induced Periostitis with Review of the Differential Diagnosis. American Journal of Roentgenology, 212, 157-165. https://doi.org/10.2214/AJR.18.19991

[11] Pineda, C. and Martínez-Lavín, M. (2013) Hypertrophic Osteoarthropathy: What a Rheumatologist Should Know about This Uncommon Condition. Rheumatic Dis- 
ease Clinics North America, 39, 383-400. https://doi.org/10.1016/j.rdc.2013.02.008

[12] Meyer, H.J., Leifels, L., Bach, A.G., et al. (2017) Secondary Hypertrophic Osteoarthropathy Caused by Non-Pleural or Pulmonary Tumors. Medicine (Baltimore), 96, e7985. https://doi.org/10.1097/MD.0000000000007985

[13] Ito, T., Goto, K., Yoh, K., Niho, S., Ohmatsu, H., Kubota, K., Nagai, K., Miyazaki, E., Kumamoto, T. and Nishiwaki, Y. (2010) Hypertrophic Pulmonary Osteoarthropathy as a Paraneoplastic Manifestation of Lung Cancer. Journal of Thoracic Oncology, 5, 976-980. https://doi.org/10.1097/JTO.0b013e3181dc1f3c

[14] Davis, M.C. and Sherry, V. (2011) Hypertrophic Osteoarthropathy as a Clinical Manifestation of Lung Cancer. Clinical Journal of Oncology Nursing, 15, 561-563. https://doi.org/10.1188/11.CJON.561-563

[15] Chakraborty, R.K. and Sharma, S. (2018) Secondary Hypertrophic Osteoarthropathy. In: StatPearls, Treasure Island, FL. https://www.ncbi.nlm.nih.gov/books/NBK513342/

[16] Kozak, K.R., Milne, G.L., Bentzen, S.M. and Yock, T.I. (2012) Elevation of Prostaglandin E2 in Lung Cancer Patients with Digital Clubbing. Journal of Thoracic Oncology, 7, 1877-1878. https://doi.org/10.1097/JTO.0b013e3181fc76a9

[17] Pourmorteza, M., Baumrucker, S.J., Al-Sheyyab, A. and Da Silva, M.A. (2015) Hypertrophic Pulmonary Osteoarthropathy: A Rare but Treatable Condition in Palliative Medicine. Journal of Pain and Symptom Management, 50, 263-267. https://doi.org/10.1016/j.jpainsymman.2015.02.005

[18] Fang, Y.H., Hsu, C.C., Hsieh, M.J., Hung, M.S., Tsai, Y.H. and Lin, Y.C. (2017) Impact of Hypertrophic Pulmonary Osteoarthropathy on Patients with Lung Cancer. OncoTargets and Therapy, 10, 5173-5177. https://doi.org/10.2147/OTT.S139558

[19] Birch, E., Jenkins, D. and Noble, S. (2011) Treatment of Painful Hypertrophic Osteoarthropathy Associated with Non-Small Cell Lung Cancer with Octreotide: A Case Report and Review of the Literature. BMJ Supportive \& Palliative Care, 1, 189-192. https://doi.org/10.1136/bmjspcare-2011-000052 